\title{
Survey and analysis of visual acuity of Kazakhs in different lighting environments
}

\author{
C.W. Zhang', J.H. Xü ${ }^{2}$ Y.L. Wang ${ }^{2}$, W. Xu ${ }^{1}$ and K. $\mathrm{Li}^{2}$ \\ ${ }^{1}$ Department of First Clinical Medical College, \\ Nanjing University of Chinese Medicine, Nanjing, China \\ ${ }^{2}$ Department of Ophthalmology, \\ The Affiliated Hospital of Nanjing University of Chinese Medicine, \\ Nanjing, China \\ Corresponding author: J.H. Xu \\ E-mail: cwdoccn@163.com
}

Genet. Mol. Res. 13 (2): 2451-2457 (2014)

Received May 23, 2013

Accepted October 2, 2013

Published April 3, 2014

DOI http://dx.doi.org/10.4238/2014.April.3.17

\begin{abstract}
The effect of different lighting environments on the vision and refractive error were investigated in 427 Kazakhs (828 eyes) aged from 40 to 60 years old, of which 279 were pastoral (546 eyes) and 148 were urban (282 eyes). Pastoral Kazakhs use natural illumination, whereas city Kazakhs mainly use artificial illumination. Of all cases, $19.1 \%$ (54 cases) had a vision of 0.4 to $0.5,20.9 \%$ (59 cases) had 0.6 to 0.8 , and $17.7 \%$ (50 cases) had above 1.0 . However, the visual acuity distribution of the pastoral Kazakhs had a more obvious characteristic, which was mainly concentrated above 0.6 . The vision of $25.1 \%$ (137) of cases was 0.6 to 0.8 , whereas $58.4 \%$ (319) of cases had vision above 1.0. There were more cases with vision above 1.0 in the pastoral Kazakhs compared to the city Kazakhs $(\mathrm{P}<0.05)$. The diopter of the city Kazakhs was between $0 \mathrm{D}$ and $-4.0 \mathrm{D}$, whereas that of the pastoral Kazakhs was between +2.0 D and -2.0 D. Diopters between $+2.0 \mathrm{D}$ and $0 \mathrm{D}$ or less than $3.0 \mathrm{D}$ differed significantly between the two groups. Daylight lamps were the main illumination photosources of the city Kazakhs. Artificial light illuminated 70.9\% (105 cases) of the city
\end{abstract}


Kazakhs for more than $6 \mathrm{~h}$. By contrast, natural light illuminated $75.3 \%$ ( 210 cases) of the pastoral Kazakhs for an outdoor activity time of more than $9 \mathrm{~h}$. These results suggest that poor lighting environment is a very important factor contributing to refractive error.

Key words: Light environment; Refractive error; Visual acuity

\section{INTRODUCTION}

Myopia is a vision condition in which close objects are seen clearly, whereas objects further away appear blurred. Myopia occurs if the eyeball is too long or if the cornea, the clear front cover of the eye, has too much curvature. As a result, the light entering the eye is not focused correctly, and thus distant objects appear blurred. A high degree of myopia is associated with a number of sight-threatening pathologies (Saw et al., 2005; Leo and Young, 2011).

Myopia is rare in infancy, but increases steadily in prevalence with age, ultimately affecting approximately 25 to $50 \%$ of young adults in Western countries, and up to $80 \%$ of young adults in parts of Southeast Asia (Gilmartin, 2004; Morgan and Rose, 2005).

To date, global myopia cases are most prevalent in societies where children watch television and play computer games instead of playing outside. In Hong Kong and Tokyo, 30 to $50 \%$ of 12-year-old children are myopic; in the United States, the rate is around $20 \%$ for this age group (Saw et al., 2005; Hess et al., 2006; Wallman and Nickla, 2010; Chen et al., 2011).

Genetic factors play an important role in influencing refractive development (Chen et al., 2011). Experiments in animals from a range of taxonomic orders, including primates, have shown that the visual environment (including the level of illumination during the day) can also influence refractive development (Gottlieb et al., 1992; Napper et al., 1992; Wildsoet, 1997; Liu et al., 2004; Wallman and Winawer, 2004; Norton et al., 2006; Ashby and Schaeffel, 2010; Cohen et al., 2011, 2012). However, only a few epidemiological survey results exist demonstrating this conclusion.

In the present study, we examined the visual acuity outcome of two groups of Kazakhs with different lifestyles. The lighting environment of the two groups differs because of illumination factors, which provided an advantageous condition to investigate the visual acuity outcome of the two groups as well as any related influencing factors.

\section{MATERIAL AND METHODS}

\section{Objects}

This study was conducted in accordance with the Declaration of Helsinki and with approval from the Ethics Committee of the Affiliated Hospital of Nanjing University of Chinese Medicine. Written informed consent was obtained from all participants. We selected Kazakhs living in Yili City of the Xinjiang Province who were willing to participate in the study. Some of the Kazakhs still live in the pastoral area and use mostly natural illumination in their lifestyle, with artificial lighting being used only for very short periods. The other group of Kazakhs had moved into Yili City and their lifestyle had to be changed; they mostly work indoors and use mostly artificial illumination. These two groups of Kazakhs maintain their original 
food preferences, and were thus identical subjects living under different lighting environments, which was a suitable condition for this visual acuity outcome study.

We randomly investigated 427 Kazakhs ( 828 eyes), aged from 40 to 60 years old, from November 2005 to November 2006. We investigated these subjects stochastically: 279 subjects were pastoral Kazakhs (546), with an average age of $47.27 \pm 1.35$ years, of which 161 were males (313 eyes) and 118 were females (233 eyes); 148 subjects were urban Kazakhs (282 eyes), with an average age of $50.32 \pm 1.79$ years, of which 67 were males (124 eyes) and 81 were females (158 eyes). All subjects underwent an ocular region routine inspection and answered a survey questionnaire. Kazakhs affected by other vision impairments or ophthalmopathies were excluded. The study was conducted in the Xinjiang Uygur Autonomous Region and Yili Kazakh Autonomous Prefecture. The Chinese medicine hospital was used to identify the suitable boundary. The ophthalmology department, the best local medical service unit, was responsible for the fieldwork.

\section{Methods}

The visual acuity inspection was conducted by an oculist using the international standard visual chart. The subjects' eyesight and ocular region situation were checked through a routine inspection. instruments.

Refraction inspection was conducted using an automatic computer and other optical

The survey questionnaire inquired about the subjects' outdoor activity time, sleep time, lighting-up time, and the type of lighting source used (incandescent lamp, daylight lamp, candle light, flare).

\section{Statistical analysis}

Data obtained from the two groups were evaluated using SPSS 11.5. The data were compared using the $\chi^{2}$ test with $\mathrm{P}<0.05$ indicating statistical significance.

\section{RESULTS}

\section{Visual acuity}

The urban Kazakh subjects' visual acuity distribution was relatively even: 19.1\% (54) of the subjects' vision was 0.4 to $0.5,20.9 \%$ (59) was 0.6 to 0.8 , and $17.7 \%$ (50) was 1.0 . In contrast, the pastoral Kazakhs subjects' visual acuity distribution showed an obvious characteristic: it was mainly concentrated above 0.6 . The vision of $25.1 \%$ (137) of the subjects was 0.6 to 0.8 , whereas $58.4 \%$ (319) had vision above 1.0 (Table 1). The visual acuity of the A and $\mathrm{B}$ groups were LP -0.5 and $\geq 1.0$, respectively, which indicated a significant difference. The visual acuity of 0.6 to 0.8 did not indicate an obvious difference.

\section{Refraction condition}

The urban Kazakhs' diopter values were relatively distributed in the plain glass and 
were less than $4.0 \mathrm{D}$, of which $15.2 \%$ (43) were plain glasses, $23 \%(65)$ were $\leq-2.0 \mathrm{D}, 19.1 \%$ (54) were $\leq-3.0 \mathrm{D}$, and $12.1 \%$ (34) were $\leq-4.0$ D. However, the pastoral Kazakhs' diopter distribution assumed a central tendency and mainly concentrated in the $\leq+2.0 \mathrm{D}$ and $\leq-2.0 \mathrm{D}$ range, of which $44.3 \%$ (242) were plain glasses, $30.8 \%$ (168) were $\leq+2.0 \mathrm{D}$, and $18.5 \%$ (101) were $\leq-2.0 \mathrm{D}$ (Table 2). There were two groups of crowd diopters for $\leq+2.0$ : the plain glass group and the $\leq-3.0$ group, and the population distributions differed significantly (Table 2).

Table 1. Uncorrected visual acuity (UCVA) of the urban Kazakh clansman and the pastoral area Kazakh clansman exposure $(\%)$.

\begin{tabular}{|c|c|c|c|c|c|c|c|}
\hline \multirow[t]{2}{*}{ Group } & \multicolumn{7}{|c|}{ Uncorrected visual acuity exposure } \\
\hline & LP-0.09 & $0.1-0.12$ & $0.15-0.2$ & $0.25-0.3$ & $0.4-0.5$ & $0.6-0.8$ & $\geq 1.0$ \\
\hline Urban Kazakh clansman & $25(8.9)$ & $29(10.3)$ & $38(13.5)$ & $27(9.6)$ & $54(19.1)$ & $59(20.9)$ & $50(17.7)$ \\
\hline Pastoral area Kazakh clansman & $6(1.1)$ & $8(1.5)$ & $18(3.3)$ & $10(1.8)$ & $48(8.8)$ & $137(25.1)$ & $319(58.4)$ \\
\hline$\chi^{2}$ & 31.12 & 33.88 & 30.55 & 26.12 & 18.47 & 1.79 & 124.65 \\
\hline$P$ & $<0.001$ & $<0.001$ & $<0.001$ & $<0.001$ & $<0.001$ & 0.196 & $<0.001$ \\
\hline
\end{tabular}

Table 2. Diopter of the urban Kazakh clansman and the pastoral area Kazakh clansman exposure.

\begin{tabular}{lllccccccc}
\hline Group & \multicolumn{7}{c}{ Diopter } \\
\cline { 2 - 9 } & $>+2.0$ & $\leq+2.0$ & $\leq+2.0$ and $\geq-2.0$ & $\leq-2.0$ & $\leq-3.0$ & $\leq-4.0$ & $\leq-5.0$ & $\leq-6.0$ & $>-6.0$ \\
\hline Urban Kazakh clansman & $4(1.4)$ & $16(5.7)$ & $43(15.2)$ & $65(23.0)$ & $54(19.1)$ & $34(12.1)$ & $22(7.8)$ & $32(11.3)$ & $12(4.3)$ \\
Pastoral area Kazakh clansman & $1(0.2)$ & $168(30.8)$ & $242(44.3)$ & $101(18.5)$ & $24(4.4)$ & $8(1.5)$ & $2(0.4)$ & & \\
$\chi^{2}$ & 4.73 & 67.76 & 69.64 & 2.40 & 47.44 & 43.32 & 36.52 & \\
$\mathrm{P}$ & 0.048 & $<0.001$ & $<0.001$ & 0.143 & $<0.001$ & $<0.001$ & $<0.001$ & \\
\hline
\end{tabular}

\section{Lighting source and lighting-up time}

Questionnaire data revealed that the urban Kazakhs mostly engage in indoor activities and use daylight lamps as the main light source. Of these subjects, 70.9\% (105 subjects) spend 6 $\mathrm{h}$ a day under artificial photosource illumination. By contrast, the pastoral area Kazakhs mostly engage in outdoor activities and primarily use the entire spectrum of natural light for illumination; $75.3 \%$ (210 subjects) of them spend $9 \mathrm{~h}$ a day engaged in outdoor activities, and $86.7 \%$ (242 subjects) use an indoor artificial photosource of illumination for only 1 to $3 \mathrm{~h}$ per day (Table 3 ). The incandescent lamp is the main lighting source, but two of the subjects reported using oil lamps.

\begin{tabular}{|c|c|c|c|c|c|c|c|}
\hline \multirow[t]{2}{*}{ Group } & \multicolumn{3}{|c|}{ Duration of the artificial illumination (Time) } & \multicolumn{4}{|c|}{ Duration of the outdoor activity (Time) } \\
\hline & $1-3 \mathrm{~h}$ & $4-6 \mathrm{~h}$ & $>6 \mathrm{~h}$ & $1-3 \mathrm{~h}$ & $4-6 \mathrm{~h}$ & $7-9 \mathrm{~h}$ & $>9 \mathrm{~h}$ \\
\hline $\begin{array}{l}\text { Urban Kazakh clansmen } \\
\text { Pastoral area Kazakh clansmen }\end{array}$ & $\begin{array}{c}4(2.7) \\
242(86.7)\end{array}$ & $\begin{array}{l}39(26.4) \\
31(11.1)\end{array}$ & $\begin{array}{c}105(70.9) \\
6(2.2)\end{array}$ & $\begin{aligned} 99(66.9) \\
1(0.4)\end{aligned}$ & $\begin{array}{c}34(23.0) \\
5(1.8)\end{array}$ & $\begin{array}{l}14(9.5) \\
63(22.6)\end{array}$ & $\begin{array}{c}1(0.7) \\
210(75.3)\end{array}$ \\
\hline
\end{tabular}

\section{DISCUSSION}

The development of society resulted in a big change in the human visual environment. We can divide the visual environment into three main types: 1) pollution of the outdoor visual 
environment, such as a wall made of glass; 2) pollution of the indoor visual environment, such as indoor light, which is not good for human health; 3) pollution of part of the visual environment, such as light from books, computer screens, and so on. The eye is the target organ of light. Staring at an artificial visual environment may affect one's visual function. According to previous investigations, the rate of myopia among high school and college students in China is more than $70 \%$. Experts suggested that aside from bad eye-use habits, the visual environment is the major cause of myopia.

The present survey showed that pastoral Kazakhs are mostly active outdoors, with good open field vision on the pastoral area that is full of natural light, and are exposed to relatively less artificial light. However, the environment of urban Kazakhs is opposite. The results indicated an obvious difference in the visual environment of the two groups of Kazakhs with respect to the lighting source, the amount of time light is used, and the lighting environment. A daylight lamp is the main lighting source of urban Kazakhs, whereas natural light is the pastoral Kazakhs' primary source of illumination. The urban Kazakhs are exposed to more artificial illumination than pastoral Kazakhs. Urban Kazakhs often see ceramic tiles, whitewashed walls, and book paper, whereas pastoral Kazakhs often see lawns and tents. The factor of light reflection of smooth whitewashed walls and book paper reaches as high as $90 \%$, which is $10 \%$ higher than that of the lawns, forests, or the surface of decoration with coarse surface (Saw et al., 2005).

This survey showed that the incidence of myopia in urban Kazakhs was very high, with only $17.7 \%$ (50 eyes) of them having a vision of $1.0 \mathrm{D}$ and above, whereas $58.4 \%$ of the pastoral Kazakhs (319 people) had 1.0 D vision. These values indicated a significant difference. The pathogenesis of myopia is complicated, with several studies demonstrating its pathogenesis from different perspectives, including hereditary factors (Liang et al., 2006), environmental factors (Hammond et al., 2001; Liang et al., 2006; Wojciechowski et al., 2013), race factors, and so on. Hereditary factors play a key role in the incidence of myopia in different races, whereas environmental factors play an influential role in the incidence of myopia within races. The environmental factors related to the pathogenesis of myopia are quite complex, including short distance from work objects, reading habits, nutrition, presence of other diseases, and so on. Epidemiological investigations have indicated that the incidence of benign myopia is related to short distance from a work object: the shorter the distance from a work object, the higher the incidence of myopia.

Ophthalmologists generally attribute myopia to the short distance from work objects, bad habits of using the eyes, hereditary factors, and other environmental factors (Lin et al., 2012; Morgan et al., 2012). However, there are no reports evaluating the pathogenesis of myopia from the perspective of "the unscientific use of light sources". Research conducted by Israel's senior oculist, Dr. Yossi Mandel (Mandel et al., 2008), indicated that a child was more likely to have good vision if they were born in the winter or autumn. Another report from the August issue of the magazine Ophthalmology indicated that the rate of myopia was $24 \%$ higher for people born in June and July than in people born in December and January. The researchers suggested that premature exposition in natural light could potentially have long-term influences on the growth of newborns and increase the child's incidence of myopia. In addition, this mechanism is possibly related to the melatonin secreted by the pineal body. The body secretes massive melatonin during sleep and the secretion stops after dawn along with the photic stimulation of vision. Because the light time in June and July is longer, the secretion of melatonin is reduced, causing elongation of the eyeball, and thereby increasing the incidence 
of myopia. In this study, the urban and pastoral Kazakhs retained the same national customs, diet, and writing culture. The main difference between the two groups is that the urban Kazakhs use more artificial illumination. This study found that the incidence of myopia in urban Kazakhs was higher than that of the pastoral Kazakhs. The refraction condition among them also differed. We thought that the environmental factor would have played the biggest role in the results. However, after analyzing the survey results of two groups of Kazakhs, we discovered that they use different illumination lighting-up time and refraction conditions. Thus, we suggest that the difference in the incidence of myopia is related to the use of artificial illumination and the unhealthy light environment. The results of this survey are in agreement with that of the Israeli research. Our results suggested that illumination influences the secretion of melatonin; however, more evidence is needed to verify that melatonin is a factor contributing to the incidence of myopia.

In this study, the artificial light changed the urban Kazakh's lighting environment, lifestyle, and visual activity. Urban Kazakhs spend most of their time inside the house, accept more artificial light, and do more short distance work, such as watching television, playing on the computer, reading, and so on. By contrast, natural light is the pastoral Kazakhs' main lighting source. They do more outdoor activities and conduct their activities in larger areas; therefore, their eyes can better adjust to the environment. Therefore, consistent with the findings of previous studies, we conclude that artificial light has changed the urban Kazakhs' visual activity, causing a high incidence of myopia (Jones et al., 2007; Rose et al., 2008; Dirani et al., 2009; Guggenheim et al., 2012). However, we cannot neglect the possibility that the change of the light environment is only one factor contributing to the incidence of myopia.

\section{REFERENCES}

Ashby RS and Schaeffel F (2010). The effect of bright light on lens compensation in chicks. Invest. Ophthalmol. Vis. Sci. 51: 5247-5253.

Chen YP, Hocking PM, Wang L, Povazay B, et al. (2011). Selective breeding for susceptibility to myopia reveals a geneenvironment interaction. Invest. Ophthalmol. Vis. Sci. 52: 4003-4011.

Cohen Y, Belkin M, Yehezkel O, Solomon AS, et al. (2011). Dependency between light intensity and refractive development under light-dark cycles. Exp. Eye Res. 92: 40-46.

Cohen Y, Peleg E, Belkin M, Polat U, et al. (2012). Ambient illuminance, retinal dopamine release and refractive development in chicks. Exp. Eye Res. 103: 33-40.

Dirani M, Tong L, Gazzard G, Zhang X, et al. (2009). Outdoor activity and myopia in Singapore teenage children. $B r . J$. Ophthalmol. 93: 997-1000.

Gilmartin B (2004). Myopia: precedents for research in the twenty-first century. Clin. Experiment. Ophthalmol. 32: 305-324.

Gottlieb MD, Nickla DL and Wallman J (1992). The effects of abnormal light/dark cycles in the development of form deprivation myopia. Invest. Ophthalmol. Vis. Sci. 33: 1052.

Guggenheim JA, Northstone K, McMahon G, Ness AR, et al. (2012). Time outdoors and physical activity as predictors of incident myopia in childhood: a prospective cohort study. Invest. Ophthalmol. Vis. Sci. 53: 2856-2865.

Hammond CJ, Snieder H, Gilbert CE and Spector TD (2001). Genes and environment in refractive error: the twin eye study. Invest. Ophthalmol. Vis. Sci. 42: 1232-1236.

Hess RF, Schmid KL, Dumoulin SO, Field DJ, et al. (2006). What image properties regulate eye growth? Curr. Biol. 16: 687-691.

Jones LA, Sinnott LT, Mutti DO, Mitchell GL, et al. (2007). Parental history of myopia, sports and outdoor activities, and future myopia. Invest. Ophthalmol. Vis. Sci. 48: 3524-3532.

Leo SW and Young TL (2011). An evidence-based update on myopia and interventions to retard its progression. J. AAPOS 15: $181-189$

Liang CL, Wang HS, Hung KS, Hsi E, et al. (2006). Evaluation of MMP3 and TIMP1 as candidate genes for high myopia in young Taiwanese men. Am. J. Ophthalmol. 142: 518-520.

Lin Z, Zhang YC, Qiao LY, Rong SS, et al. (2012). Advances in near work-induced transient myopia. Zhonghua Yan Ke 
Za Zhi 48: 657-661.

Liu J, Pendrak K, Capehart C, Sugimoto R, et al. (2004). Emmetropisation under continuous but non-constant light in chicks. Exp. Eye Res. 79: 719-728.

Mandel Y, Grotto I, El-Yaniv R, Belkin M, et al. (2008). Season of birth, natural light, and myopia. Ophthalmology 115: 686-692.

Morgan I and Rose K (2005). How genetic is school myopia? Prog. Retin. Eye Res. 24: 1-38.

Morgan IG, Ohno-Matsui K and Saw SM (2012). Myopia. Lancet 379: 1739-1748.

Napper GA, Vingrys AJ, Squires MA and Vessey GA (1992). Influence of continuity of exposure and length of light/dark cycle on occlusion induced myopia. Invest. Ophthalmol. Vis. Sci. 33: 711.

Norton TT, Amedo AO and Siegwart JT Jr (2006). Darkness causes myopia in visually experienced tree shrews. Invest. Ophthalmol. Vis. Sci. 47: 4700-4707.

Rose KA, Morgan IG, Ip J, Kifley A, et al. (2008). Outdoor activity reduces the prevalence of myopia in children. Ophthalmology 115: 1279-1285.

Saw SM, Gazzard G, Shih-Yen EC and Chua WH (2005). Myopia and associated pathological complications. Ophthalmic Physiol. Opt. 25: 381-391.

Wallman J and Winawer J (2004). Homeostasis of eye growth and the question of myopia. Neuron 43: 447-468.

Wallman J and Nickla DL (2010). The Relevance of Studies in Chicks for Understanding Myopia in Humans. In: Myopia: Animal Models to Clinical Trials (Beuerman RW, Saw SM, Tan DTH and Wong TY, eds.). Singapore: World Scientific, 29-266.

Wildsoet CF (1997). Active emmetropization-evidence for its existence and ramifications for clinical practice. Ophthalmic Physiol. Opt. 17: 279-290.

Wojciechowski R, Yee SS, Simpson CL, Bailey-Wilson JE, et al. (2013). Matrix metalloproteinases and educational attainment in refractive error: evidence of gene-environment interactions in the Age-Related Eye Disease Study. Ophthalmology 120: 298-305. 